\title{
Célia BELIM*
}

\section{E-public Relations in Health Organizations: How EURORDIS-Rare Diseases Europe Uses the Website and Facebook to Communicate with Key Publics}

\begin{abstract}
This article focuses on how EURORDIS-Rare Diseases Europe uses e-Public Relations to communicate and construct and strengthen relations with key publics, concretely the patients/members and journalists. Grounded on rhetorical theory and on a triple (qualitative, quantitative, and rhetorical) analysis to content, the study explores the website, Facebook page and press releases of EURORDIS. The results show that the EURORDIS' website encompasses six types of content: information, clarification, personalization, support, appeal, and empowerment. In Facebook $(\mathrm{N}=160)$, the most significant issue is "reference of an event promoted by EURORDIS" (59,4\%), "information and appeal" (40,0\%) is the most used content type, and "text and photo" (77,5\%) is the preferable resource used. Among the rhetorical devices ( $\mathrm{N}=103)$, the most frequent is "use of question". The other rhetorical devices used are repetition, mix of information and appeal, personalization, exclamation mark (logos), encouragement of an emphatic spirit (pathos), and reference to elite members (ethos). The most expressive issue in press releases $(\mathrm{N}=17)$ is "public support/promotion of actions benefiting the cause of rare diseases" and the most frequent sources are EURORDIS' direction. Rhetorical analysis reveals the focus on the target public - journalists -, confirmed by the use of a predominantly informative language style.
\end{abstract}

Keywords: e-Public Relations (e-PR), EURORDIS, rare diseases, digital media, press releases

\section{Introduction}

Health is "central to our lives, a major topic of news, is politicised, underresourced, and a subject open to alternative perspectives so it is unsurprising that this sector of the public relations industry is expanding" (L'Etang, 2006, p. 254). One of the ways for preventing diseases is the transfer of health information by educating the patients and encouraging them to search for related information (Lalazaryan \& Zare-Farashbandi, 2014). Many people lose their lives or suffer serious complications from diseases due to lack of knowledge about prevention methods (Lalazaryan \& Zare-Farashbandi, 2014). In this sense, online communication of health organizations and online media can provide useful information. These actors explore the benefits of communication, accomplishing the postulates that "communication is all we have" and "it

* Universidade de Lisboa (ISCSP-Ulisboa, Portugal) cbelim@iscsp.ulisboa.pt 
is what makes us human" (Macnamara, 2017). The vastly expanded electronic capacity collects and communicates a broader world opinion to more people, more quickly than at any other past time (McKie \& Munshi, 2011, pp. 59-60). Online opportunities accelerate the rapidity of change (McKie \& Munshi, 2011, p. 199) and the Internet is the most powerful relation-building tool the organizational world has ever witnessed (Haig, 2000, p. 3).

Regarding the online performance of health organizations, they need to exploit more fully the potential of new digital technologies to strengthen prevention and care $(\mathrm{OECD} / \mathrm{EU}$, 2018, p. 13). Davies (2016), for example, argues that medical and life sciences have not fully exploited the potential of social media sites, including Facebook. This online performance, which influences people's lives and seeks to build relationships between organizations and key publics (Pang, Shin, Lew \& Walther, 2016; Vasquez \& Taylor, 2001, p. 139), can be named as online public relations or e-PR. In a simple definition, e-PR refers to public relations (PR) on the Internet (Haig, 2000, p. 3). e-PR "has become more than a necessity, representing a communication opportunity" (Petrovici, 2014, p. 81). Exploring the power of the internet, e-PR represents an alternative to other forms of relationship building, communication and interaction (Petrovici, 2014, p. 83). This article makes sense within the "Web PR age" - announced by Hurme (2001) - in which the keywords for PR practitioners are interactivity, dialogue, dynamism, involvement.

"What is said about you is more valuable than what you say about yourself" (Levine, 2003, p. 12). But "what you say about yourself" influences "what is said about you". So, this article, aware of one of the PR's trends, such as the potential of "compelling content" (Ehrlich \& Harrigan, 2019), focuses on what and how EURORDIS says about itself and rare diseases, and about its messages and communicational efforts to stablish and strengthen relationships with rare diseases' patients and journalists. EURORDIS is a unique, non-profit alliance of 837 rare disease patient organizations from 70 countries that work together to improve the lives of the 30 million people living with a rare disease in Europe (https://www.eurordis.org/whowe-are). e-PR can be particularly significant among health field specially among rare diseases, as it is likely that the number of patient groups on social media associated with specific pathogenic genetic mutations will increase substantially, once genome-wide analyses, such as exome or whole-genome sequencing, become more commonplace (Davies, 2016).

Bañón Hernández (2007) concludes that patients with rare diseases, because of their systematic exclusion from the main discussion forums, are considered a minority group with generally little capacity to exert any significant influence on political and social issues. In this line, one evidence from the studies of the Centro de Investigación Biomédica en Red de Enfermedades Raras (CIBERER) is that the training and preparation of communicators influence the quality of information, and the information's effectiveness would increase if there was a correlation between the official sources' discourse on the what is done and what is actually accomplished (Bañón Hernández, Alcaraz, Almela \& Sanchis, 2011). Therefore, there is a need for patients with rare diseases and organizations working in this field to gain an effective voice in the public sphere.

Practitioners of PR need to develop a structured understanding of the issues they are influencing in order to perceive the attitudes of others (Watson \& Noble, 2014, p. 2). As Cuenca Fontbona (2012) remembers: if for Ivy Lee PR is an art, for Bernays it is an application of social sciences in which the research of publics has an essential role (p. 72). Ki, Kim and Ledingham (2015) and Bowen, Hung-Baesecke and Chen (2016), for example, agree with the statement that, today, organization-publics relationships (OPRs) are central to PR. Bowen et al. (2016) refer that ethics is a foundational concept in building trusting OPRs. 
EURORDIS' website and Facebook page were the two online platforms analyzed. In addition, to perceive the contents intentionally made for media consumption, the press releases, available on EURORDIS website, were explored.

The website is a "key of direct communication" (Murray, 2010). Murray (2010) explains that every organization with a public profile should have a website and that, from the PR perspective, the website has become a vital communication tool as it is "often the first port of call" and will deliver the first tangible impression of the organization. On the other hand, Facebook can be "a great way to build and engage communities of advocates" (Wilson, 2012, p. 67), which can be particularly pertinent in the divulgation of rare diseases, which do not have enough visibility. PR practitioners "need to understand the social network landscape" (Howell, 2012, p. 11) and how social media constrain and enable PR practice and desired responses from target audiences (Lipschultz, 2015, p. 21), in order to improve their performance and communication's results.

It were also analyzed the press releases of EURORDIS, once the media are a significant player in promoting a healthier society by providing useful health information to their audiences and delivering news about the latest developments on health issues (Cho, 2006, p. 116) and the press releases, among the communication tools used by PR practitioners, are one of "the most tried and true sources of information for journalists" (Park \& Reber, 2010, p. 40). Considering the potential of press releases for shaping the public health agenda via the mass media, the examination of health organizations' press releases is a pivotal step in determining their PR efforts to frame media coverage of health news (Park \& Reber, 2010, p. 40). In addition, by disseminating press releases, health organizations are able to better frame their version of the social reality related to the health problems they represent and to portray themselves as reliable and credible resources for public health (Park \& Reber, 2010, p. 43). Finally, how public relations practitioners frame their health messages to the media may have a direct impact on the public's health perceptions and decisions (Ruăo, Lopes, Marinho \& Araújo, 2012, pp. 69-70; Tanner, 2004b, p. 24).

This article grounds on rhetorical theory, trying to offer some response to the call for rhetorical contributions to health pedagogy and to the understanding of health communication practices (Campbell, 2017, pp. 8, 12).

\section{To be "e" or not to be "e", it is the question! e-PR in health field}

Independently of being "e" or not, PR "is and always will be about human relationships" (Marlow, 1996, p. 161). As PR has to follow the public appetite for media, this is fast becoming internet based (Phillips \& Young, 2009, p. 101).

PR is a tool through which organizations try to exercise the influence they have on the way we live our lives with particular outcomes in mind, but it is also a practice that has agency beyond organizational objectives (Edwards, 2018). PR "is what you pray for" and not "what you pay for" (Levine, 2003, p. 12).

One of the basic definitions of PR refers it as the management of communication between an organization and its publics (Grunig \& Hunt, 1984, p. 6). Communication is a core word in the heart of PR. Bernays (2013) explains that "public understanding and support is basic to existence in our competitive system. To know how to get along with the public is important for everyone" (p. 7) and Phillips and Young (2009) clarifies that PR "is largely depend- 
ent on communication" (p. 101). Another association of ideas is that PR "arises at points of societal change and resistance" (Phillips \& Young, 2009, p. 13) and its success is committed to the credibility's maintenance (Newsom \& Haynes, 2010, p. 274).

Haig (2000) states that having an e-PR perspective involves learning the three Rs: 1. Relations: e-PR focuses on building relations, which are long-term and mutually beneficial, through interacting with different publics; 2 . Reputation: it is the most important organizational asset and e-PR is the art of managing online reputation; 3. Relevance: it is needed that everything that an organization puts online is directly relevant to its publics (pp. 5-6).

In e-PR, "e" is for electronic and concerns every aspect of the Internet, "P" is for public, stressing that the idea of a singular public is now outdated, and " $R$ " is for relations, stablishing that building relations between organizations and its publics is the key to success on the Internet (Haig, 2000, p. 3).

As the rhetorical theory can help PR to account for the symbolic aspects of communication, which arguably are the heart of PR activity (Ihlen, 2008), the present study can be grounded on it. The rhetorical theory focuses on relationships, on how they are constructed between organizations (in this case, EURORDIS) and key publics (patients/members and journalists). This theory reflects the effort to shaping knowledge, images and opinions, as well as to being convincing and motivating others. The theory also features how the PR process becomes enriched through the role co-created. Shared meaning functions in society as a blend of mind and self (Heath \& Frandsen, 2008). Heath says that PR can add value to society by assuring that choices become enlightened, risks are ethically managed, and relationships are mutually developed (Black, 2014, p. 36). This value or potential is perfectly suited to health field.

To optimize the communication's results, e-PR has to disseminate, through the publics, persuasive communication. If where there is meaning there is persuasion (Burke, 1969, p. 72), all communication - which brings together meanings - is persuasive. Persuasion may attempt to influence beliefs, attitudes, intentions, motivations or behaviors (Gass \& Seiter, 2010 , p. 33). In the persuasive way, Aristotle (IV century BC/2005) points to three means of persuasion:

- Ethos: Those derived from the character of the communicator (credibility, ethos);

- Pathos: Those derived from emotion aroused in the public (emotion, pathos); and

- Logos: Those based on evidence, true or probable arguments and logically extracted inferences capable of making the audience adhere to the thesis put forward (reason, the logos) (IV century BC/2005, p. 37).

Social media, used within health care contexts for communication purposes, is increasing and becoming more acceptable (Burke-Garcia \& Scally, 2014; Moorhead, 2017). Specifically, the digital tools are likely to enable: (a) improved interactions with others; (b) more available, shared, and tailored information; (c) increased accessibility and widening access; and (d) increased peer/social/emotional support. These are some of numerous benefits of social media for healthcare communication (Moorhead, 2017).

In spite of recognizing that digital media have an ability to increase the reach of public health research and communication, as well as drive measurable behavior change, BurkeGarcia and Scally (2014) identify that there is an absence of both deep and wide understanding of the opportunities within digital media, that a smart and strategic planning for its widespread use is not a common practice and that rigorous evaluative studies of its effectiveness are few and far between. 
Ramanadhan, Mendez, Rao and Viswanath (2013) surveyed social media usage among U.S. (from Boston, Lawrence, and Worcester, Massachusetts) 166 community-based organizations conducting health promotion (CBOs) and found that almost (98\%) has a website and $70 \%$ a social media presence on Facebook, Twitter, and/or YouTube (p. 6). The top three types of content used are: organization promotion (66\%), health education/news $(24 \%)$, and crosspromotion (19\%). Regarding the ways in which CBOs leveraged the multimedia and relational aspects of the Facebook platform, 32\% included links to external links, 27\% links to internal content, $22 \%$ included a photo and less than $1 \%$ included a video. About the engagement with posts via the "like" function, $65 \%$ of posts received at least one "like". Stories with human interest, although a small proportion of overall posts, received the highest average number of "likes" per post, with an average of almost 6 "likes" per post (Ramanadhan et al., 2013, p. 7).

Kite, Foley, Grunseit and Freeman (2016) give insight into post content that maximizes user engagement and begins to fill the knowledge gap on effective use of Facebook by (Australian) public health organizations. In spite of Facebook, the most widely used social media platform, has being adopted by public health organizations for health promotion and behavior change campaigns and activities, limited information is available on the most effective and efficient use of Facebook for this purpose. The authors selected 20 eligible pages through a systematic search and coded 360-days of posts for each page. Posts were coded by: post type (e.g., photo, text only), communication technique employed (e.g., testimonial, informative) and use of marketing elements (e.g., branding, use of mascots). The results showed that video posts attracted the greatest amount of user engagement, although an analysis of a subset of the data suggested this may be a reflection of the Facebook algorithm, which governs what is and is not shown in user newsfeeds and appear to preference videos over other post types. Posts that featured a positive emotional appeal or provided factual information attracted higher levels of user engagement, while conventional marketing elements, such as sponsorships and the use of persons of authority, generally discouraged user engagement, with the exception of posts that included a celebrity or sportsperson.

Comparing the way vaccination-related webpages (514 in favor, 471 against, and 108 neutral) communicate the issue and the quality of websites, Sak, Diviani, Allam and Schulz (2016) observe that, generally, webpages holding a favorable view present more quality indicators compared to both neutral and anti-vaccination pages. Websites, holding a favorable view toward the vaccination practice, provide more vaccination-specific information themes compared to the neutral vaccination-related online sources. Higher quality of pro-vaccination websites might be explained by higher professionalism of their owners, who were more often internationally recognized medical institutions (e.g., World Health Organization - WHO, Centers for Disease Control and Prevention - CDC), while anti-vaccination websites were often operated by activists of the anti-vaccination movement, who are private citizens expressing their personal views on the topic.

\section{Rare diseases, but not rare in e-communication}

Digital media have been contributing to the awareness of rare diseases and have even assumed diagnostic functions. Castillo-Esparcia and López-Villafranca (2016) focus on communication strategies employed by rare disease patient organizations, analyzing the media portrayal of these diseases and patient organizations in Spain between 2012 and 2014. By 
carrying out a descriptive analysis of the digital communication activities performed by 143 national organizations and conducting a telephone questionnaire of a representative sample of 90 organizations, the investigators explore the association between media presence and funding and public image. They observe that increased visibility of the organizations, afforded by a growth in the coverage of the topic, increments the membership - but not donations - and also increases awareness of these diseases. Most of the organizations studied do not have a specific person responsible for communication due to lack of resources and time: they are rarely able to invest in hiring a communication specialist. Generally, communication is provided by volunteers who do not receive any type of remuneration and are likely to be women between the ages of 40 and 60. It turns out that organizations develop their communication strategies mainly through the internet. More than $80 \%$ of patient organizations have active pages. It is noted a little media-oriented option, as only $21 \%$ of organizations have a virtual press room.

However, the digital option has gained space, since more than half of organizations uses online social networks for communication purposes and views these networks as their most important and effective impact tool (Castillo-Esparcia \& López-Villafranca, 2016). Davies (2016) also observes the insights of rare diseases from online surveys, a relatively new experimental method by which information can be obtained in a direct manner and can benefit affected individuals in a short timeframe. The author advocates that this approach may be especially useful for getting an overview of the wide range of phenotypes that affect patients (many of which may not be intuitive) and for gaining information on those issues which most impair affected individuals' lives.

Liuccio et al. (2015) analyze the role of communication in rare diseases through a systematic literature review, focusing on the information patients extract from (digital and traditional) media and, secondly, on interpersonal patient-physician communication. They observe that "only 56 papers" (Liuccio et al., 2015) were found to focus on the topic and use a narrative synthesis, highlighting three specific issues (p. 3):

The source of medication information and other information on diseases: Patients perceive physicians and Internet as credible sources of medication information. The Internet offers patients with rare disease:

- Perceived and objective disease knowledge: An opportunity to connect with, acquire knowledge and support from others facing identical situations (Doyle, 2015; Lasker, Sogolow \& Sharim, 2005; Mursch \& Behnke-Mursch, 2003; Wicks et al., 2010);

- Self-diagnosis and prevention: The possibility to screen prevention, diagnosis, and treatment of the disease, and also in early identification, personalized treatment, and health management in general (e.g. Dwyer, Quinton, Morin \& Pitteloud, 2014; Kowalski, Kahana, Kuhr, Ansmann \& Pfaff, 2014);

- Self-expression and communication: It permits to express concerns that patients could hardly communicate to their doctor and to prevent disease (Hilton-Kamm, Sklansky \& Chang, 2014; Jhaveri, Schrier \& Mattana, 2013; Zaid et al., 2013);

- Health-related information and education: The access to relevant information, especially older patients with little or no education and who live without a partner.

Patients use the Internet more than they ask pharmacists for medication advice, also when dealing with side effects and drug effectiveness (Carpenter, Blalock \& DeVellis, 2012). 
- The patient-physician interaction: Communication processes, in this context, are predominately affected by the role behavior of both patient and health care provider.

- Psycho social support: Families with patients with rare diseases are negatively affected by delays-in diagnosis and by the scarcity of access to peer support groups and to psychological advice.

Specifically studying the alignment of Facebook with the priorities of rare diseases associations, Subirats et al. (2018), reinforcing results from previous studies (Reguera, 2017; Reguera, Subirats \& Armayones, 2017) and using computational analysis, find that photos are the type of posts with the highest number of reactions and engagement, while statuses are the type of posts with the highest number of comments, and events are the type of posts with more shares (p. 11). Among the word clouds, the authors discover that in Facebook the highlighted words are gratitude instead of help, life, people and children (more present in decalogue) and that differences among word clouds are grouped by level of engagement: the low engagement word cloud is related to spam messages, while medium/high engagement word clouds are related to treatments. It is also observed a high correlation between the polarity and the time of day. The authors recommend to users interested in rare diseases who want to maximize their engagement of their posts: (1) use photos in their posts; (2) update their status; (3) post content of common interest; and (4) post at midday or late at night.

The literature review shows that only a few studies have fully considered the communication role set in rare diseases and that there is no adequate attention paid to patients' health information seeking behaviors. Bouwman, Teunissen, Wijburg and Linthorst (2010) observe that, regarding rare diseases, the use of the internet may be an important tool in the diagnostic process. The authors present two cases in which concerned parents made a correct diagnosis of a lysosomal storage disorder in their child by searching the internet after a long doctor's delay. Black and Baker (2011) also have recognized the potential of digital media. The authors consider that IDEA League is an excellent example of the impact of patient advocacy groups, the Internet, and social networking on the landscape of rare diseases.

\section{Public relations-journalists: A relation of dependency in communication}

PR professionals, operating in the health field, are responsible for providing organizational definitions of health problems and solutions to the media (Park \& Reber, 2010, p. 42). Davis (2000) also mentions that PR practitioners serve as powerful mediators between journalists and the medical industry by influencing sources' abilities to gain access to journalists and managing health agendas in the media. While helping media to gather accurate and complete health information, PR professionals also can promote their health agencies' viewpoints on emerging health issues and facilitate public awareness and debates (Zoch \& Molleda, 2006).

Park and Reber (2010) analyzed health organizations' PR efforts to frame health issues through their press releases. The content analysis of 316 press releases from three health organizations - the American Heart Association, the American Cancer Society, and the American Diabetes Association - revealed that they used the medical research frame most recurrently and emphasized societal responsibility for health issues. There were differences, however, among the organizations regarding the main frames and health issues: the American Diabetes Association was more likely to focus on the issues related to social support and education, 
while the other two were more probable to address medical research and scientific news. To demonstrate their initiatives for public health, all the organizations employed the social support/educational frame most frequently. Researchers and medical doctors customarily were quoted as trusted sources in the releases.

The power of PR in health is reinforced by some particularities of health journalism, that make informational production very dependent on the technical skills of the sources - organizations, scientists or doctors (Lopes, Ruăo, Marinho \& Araújo, 2011, pp. 105-106). Some studies confirm this standpoint of view. Tanner (2004a) conducted a U.S. nationwide survey and concluded that institutional spokespersons and specialized sources have a very significant impact on the production of television health information: $60 \%$ of health journalists revealed they contacted experts very often to explain the technical information and $60 \%$ confirmed that health sources significantly influenced the news content. In the study of Turk (1986), content analyses of information subsidies and newspaper agendas, during a two-month period in 1984, supported some hypotheses: (1) conformity to journalistic norms of newsworthiness is the most important factor in a paper's decision to accept a news release; (2) the issues' agenda in news stories, using information from agency public information officers (PIOs), reflects the issue agenda and priorities of agency information subsidies; and (3) PIOs, who consider themselves as providers of persuasive propaganda, are less successful than are officials who view themselves as providers of information.

Friedman, Tanner and Rose (2013) conducted interviews with U.S. health journalists, revealing that while journalists "felt that current collaborations between health journalists and public health practitioners were good" some still cited it as lacking (p. 382). Journalists also reported personal difficulties in understanding public health information when presented to them, stating "many people with public health degrees become epidemiology-focused and not media-focused which makes it difficult to translate the data" (Friedman et al., 2013, p. 383).

\section{Method and data}

The starting question that guides the study is: How does EURORDIS-Rare Diseases Europe use e-Public Relations to communicate with key publics, concretely patients/members and journalists? Associated to this question, some research questions are formulated: 1. What is the thematic agenda of online messages?; 2 . What is the content type used in online messages?; 3. In order to explore the rhetorical practices used in online messages constructed for patients and members, what are the rhetorical devices/tactics used in these messages?; 4. Which is the most expressive type of resource used in online messages?; 5 . What is the thematic agenda of press releases?; 6. Which are the sources quoted in press releases?; 7. In order to know the rhetorical discourse constructed to communicate with journalists, what are the rhetorical devices/tactics present in press releases?; and 8. Which are the content's patterns and variations?

The specific objectives proposed are: 1. to understand the EURORDIS' use of digital media (website and Facebook page) to communicate with patients and members; and 2. to perceive how EURORDIS construct the messages, through press releases, to disseminate among journalists.

To accomplish the first objective, the messages of digital communication of EURORDIS were analyzed, concretely in the website and Facebook page. In the Facebook, the analysis 
period was one semester, concretely the last one: between January and June of 2019. The Facebook's corpus is composed with 160 posts. On 12 September 2019, EURORDIS' Facebook page had 36.120 likes and 36727 followers. The collection of data was updated at the referred date.

To fulfill the second one, the press releases - available in the website, in the item "News \& Events" and, inside it, in the sub-item "EURORDIS press releases" - were analyzed. The analysis period meets the criterion of topicality and, thus, comprises the years 2018 and 2019 (until August). In total, the corpus has 17 press releases.

The techniques used are qualitative content analysis (preparatory analysis and auxiliary for the others), content analysis (to complement quantitatively the analysis), and the rhetorical analysis. The qualitative content analysis is the most prevalent approach to the qualitative analysis of documents. It comprises a searching out of underlying themes in the materials being analyzed (Bryman, 2012, p. 557).

To operate the technique, the procedures suggested by Altheide (2004) were adopted:

Step 1: Generate an operational research question (How does EURORDIS use e-PR to communicate with patients/members and journalists through the website, the Facebook page and press releases?);

Step 2: Become familiar with the context within which the documents were / are generated;

Step 3: Become familiar with a small number of documents (contents of website and Facebook);

Step 4: Generate some categories (e.g., issue, type of content, rhetorical device, type of resource) that guide the collection of data and draft a schedule for collecting the data in terms of the generated categories. The formulation of categories was also anchored in the literature review, concretely in the references: Kite et al., 2016; Park \& Reber, 2010.

The categories and sub-categories generated were used/quantified in the (quantitative) content analysis of Facebook and press releases. Content analysis is an approach to the analysis of documents and texts, that seeks to quantify content in terms of predetermined categories and in a systematic and replicable way (Bryman, 2012, p. 290).

The rhetorical analysis is the examination of how texts persuade their audiences of their claims (Dysart-Gale 2010, p. 29). The aim of rhetorical analysis is not simply to describe the claims and arguments advanced within the discourse, but, most importantly, to identity the specific persuasive tactics/devices employed by the speaker to accomplish specific persuasive goals (O’Donohue, 2013). Traditional rhetorical analysis often "emphasize the situatedness of discourse, consider[ing] stylistic components (i.e., metaphor, trope) as key to persuasion, and culminate[ing] with a judgment about the rhetorical practice(s) being considered" (Lynch \& Zoller, 2015, p. 498). In the analysis operationalized and exploring the rhetorical theory, the rhetoric devices included in the means of persuasion, referred by Aristotle, specially the pathos and logos, were used. 


\section{How EURORDIS uses e-PR to communicate with key publics - Findings}

\section{The website: "the first port of e-PR call". Utility of content types}

The EURORDIS website encompasses six types of content: 1. Information; 2. Clarification; 3. Personalization; 4. Support; 5. Appeal; and 6. Empowerment. These types of content or practices are related to the uses that EURORDIS gives to website, an e-PR's communication tool.

In the category designated "information", it can be found some notes on "who we are" (what the EURORDIS is), "what we do" (EURORDIS' mission), "international activities" (EURORDIS' vision), "membership" (list of EURORDIS member associations), "library" (e.g., publications, activity reports, fact sheets and infographics), "our funding" (financial information, health sector corporates, top five donors), "job openings", "EURORDIS events" (summer schools, workshops), EURORDIS' advocacy for incentives, "members' news and announcements", "international rare disease events", "rare diseases in the arts" (the codification and inclusion of rare diseases in diverse arts, such dance, documentaries, movies, literature, functioning as an archive of artistic material focused on rare diseases), "EURORDIS webinars" (web seminars that provide interactive training on practical skills such as how to cultivate volunteers, social media and governance), "eNews" ("read past issues of EURORDIS' weekly newsletter"). There is a specific item, more directed to journalists, which is "EURORDIS press releases".

In the "clarification" category, EURORDIS uses contents that can contribute to better understanding and demystify some conceptions on rare diseases, such as: the document "rare diseases: understanding this public health priority", some deconstructive information, such as: "a disease or disorder is defined rare in Europe when it affects less than 1 in 2,000 citizens" (Orphan Drug Regulation 141/2000), "no existing effective cure", "there are between 6,000 and 8,000 rare diseases, $75 \%$ of rare diseases affect children, $30 \%$ of rare disease patients die before the age of $15,80 \%$ of rare diseases have identified genetic origins", "rare disease patients and their families are known to be more pro-active than patients suffering from other common illnesses", the clarification of some related concepts: rare diseases, neglected diseases, orphan diseases, orphan drugs.

The "personalization" is present in the item "Living with a Rare Disease". In this item, there are various videos with testimonial stories and a list from A to Z, according to disease name, of testimonial stories. The support grounds on statements, such: "useful to do", "good to know", "how patient groups can get involved". The appeal is anchored in some suggested behaviors, such as: "improve the safety of your medicines", "get involved", giving guidelines to individuals, patient groups and companies, "donate", "take action", "connect with others". The empowerment can be found in some titles such as: "From isolation to empowerment of patients", that focuses in the context of "insufficient scientific knowledge base and human isolation" and the solutions patients and parents have developed: a variety of "selfhelp support groups", creation of associations of patients and parents whose actions have already ensured progress in healthcare and social assistance provided to the victims, development of treatments, and in raising public awareness of this type of diseases.

In summary, the messages displayed on the website have a wide range of usefulness, allowing the recipient to find diverse issues and to satisfy different needs. 


\section{Facebook: "A great way to build and engage communities of advocates"?}

\section{Thematic agenda}

The qualitative content analysis shows that the reference of an event is a very expressive practice used by e-PR to promote EURORDIS's actions and to give visibility to the association within the online community of patients and members. To illustrate the presence of the thematic agenda, the qualitative content analysis provides some examples for issues as category:

- Reference of an event promoted by EURORDIS: "webinar to learn more about Rare2030 - Foresight in Rare Disease Policy \& how you can help shape future recommendations on rare disease policy", "join us at the EURORDIS Black Pearl Awards Ceremony!", "Live now! EURORDIS 'How to' webinar: Learn about digital health ecosystems", "Have your say in choosing the winner of the EURORDIS Photo Award 2019!", "Information on the \#ProtectERNs campaign from Genetic Alliance UK is now available in French, Spanish, German, Italian \& Portuguese", "the \#IntimateAudrey exhibition on the life of Hollywood icon \#AudreyHepburn in Brussels this weekend!", "The EURORDIS Membership Meeting 2019 begins today!";

- Reference of online resources to facilitate the access to information or/and to promote rare diseases: "Have you heard of EyeHarp? The gaze-controlled digital device enables people living with physical disabilities to learn \& play music. Find out more: http://theeyeharp.org/", "webinar on 2 May at 12.00 CET to learn more about Rare2030 Foresight in Rare Disease Policy", "Want to get the latest information from the \#raredisease community? Read our eNews and share your news too! http://ow.ly/lDYV30orxKg";

- Resources to support events or action: "Out now! Download the official poster for \#RareDiseaseDay 2019 now available via rarediseaseday.org/downloads. Share it today to show your support for the rare disease community. \#ShowYourRare";

- Attribution of an award: "Anne-Dauphine Julliand is the recipient of the EURORDIS Visual and Audio Media Award in recognition of her inspiring documentary film 'Et Les Mistrals Gagnants'. Find out more on https://blackpearl.eurordis.org/”, “@ALSLiga are the recipient of the EURORDIS Members Award in recognition of their great work in providing services and support that have significantly enhanced the quality of life of people living with amyotrophic lateral sclerosis (ALS) across Belgium and Europe";

- Happy holidays wish: "The Board of Directors and the staff of EURORDIS wish you a Happy New Year!";

- Demonstration and results of support: "Thank you to Members of European Parliament Tilly Metz patron of the event, Inese Vaidere, John Howarth MEP \& other supporters of the rare disease community", "Thank you to the 60+ MEPs \& candidates from 13 countries across Europe who have supported the \#Pledge4RD”.

\section{Utility of content types}

Applying qualitative content analysis to Facebook's corpus, the type of content can be illustrated by some examples extracted from Facebook contents:

- Information: "The gaze-controlled digital device enables people living with physical disabilities", "Intimate Audrey exhibition", "Rare Barometer survey", "The 10th World Conference on \#CorneliadeLange syndrome will take place 31 July - 4 August in Germany", "EURORDIS and Rare Diseases International met Dr Tedros, Director-General of the WHO, 
yesterday to discuss next steps towards a future collaboration to ensure people living with a rare disease are not left behind", "EURORDIS is leading the RARE-IMPACT initiative that aims to identify challenges and solutions to patients' access to \#gene and cell therapies for rare diseases with secretariat support from Dolon", "Introducing ... the recipient of the EURORDIS Photo Award 2019 DEEP DERÝN", "A brand new online shop has been launched for \#RareDiseaseDay where you can find t-shirts, jumpers and much more!";

- Appeal/invitation: "Have you heard of EyeHarp?", "Community Advisory Board in your disease area? Join a workshop to learn what's involved in starting a CAB during the EURORDIS Membership Meeting”, "Ask your returning or candidate Member of the European Parliament to pledge their support for the rare disease community", "Join the first 22q11 Northern Ireland Conference", "Would you like to contribute to shaping the next 10 years of rare disease policy? Register for a webinar on 2 May at 12.00 CET to learn more about Rare2030 - Foresight in Rare Disease Policy \& how you can help shape future recommendations on rare disease policy", "Register to join an event bringing together families and experts to discuss \& exchange on Cornelia de Lange syndrome", "Want to get the latest information from the \#raredisease community?", "Ask your returning or candidate Member of the European Parliament to pledge their support for rare diseases ahead of the European elections taking place in May!", "Are you looking to grow your rare disease network? Register for the EURORDIS Membership Meeting 2019 Bucharest", "Live now! EURORDIS 'How to' webinar: Learn about digital health ecosystems", "Take a look at the new website for more information https://rareimpact.eu/", "Want to get the latest information from the \#raredisease community? Read our eNews and share your news too!", "Get inspired to join the \#ShowYourRare campaign!", "Vote for your favourite photo to win the EURORDIS Photo Award 2019!";

- Personalization: "Ralf is a graduate of the \#EURORDISSummerSchool \& \#EURORDISWinterSchool and shares his experience of becoming an active patient advocate for rare vascular diseases", "Sergio and his family had a long diagnostic odyssey before getting a diagnosis of \#DravetSyndrome", "On \#RareDiseaseDay 2019 watch and share Lorena's story of living with Phelan-McDermid syndrome to raise awareness of rare diseases!", video of Karlo who lives with the rare disease neurofibromatosis type 1, "Anne-Dauphine Julliand is the recipient of the EURORDIS Visual and Audio Media Award in recognition of her inspiring documentary film 'Et Les Mistrals Gagnants"”, "HRH Princess Maria of Romania will show her support for the rare disease community by attending the EURORDIS \#BlackPearl Awards Ceremony on 12 February", "Russell is the recipient of the EURORDIS Volunteer Award in recognition of his exceptional work as a patient advocate for all rare eye conditions through LHON Society and as a patient board member of Ern-Eye and for all rare diseases in his work as one of EURORDIS' longstanding volunteers".

\section{Rhetorical approach}

On Facebook, some rhetorical devices are used, such as:

Logos:

- The question as a phatic or flashy element, which establishes contact, since demands a response (e.g., "Have you heard of EyeHarp?");

- Repetition: some initiatives and events are remembered in an intention to optimize the reception of the message and familiarity with it (e.g., the happy new year wishes appear in seven languages: German, Italian, Russian, Spanish, English, Portuguese, and French); 
- Information and appeal work together to optimize the potential of message, constructing a discourse that is mainly entangled in the informational and appeal functions (e.g., "There's one week left to take the \#RareBarometer survey! Is there a treatment for your rare disease? Are you able to access it? Take the survey by 30 April and share your experiences. Available here in 23 languages: http://bit.ly/eurordis-survey");

- Personalization by referring to people who experience illnesses, encouraging empathy and identification among subjects who deal with the same diseases and disorders, as well as the supportive and empathic spirit to those involved in the promotion of causes related to rare diseases (pathos);

- Exclamation mark is used as a phatic element and thus as a magnet for the reader's attention (e.g., "New!", “Live now!").

Ethos:

- The reference to "elite figures" such as Audrey Hepburn, affected by a rare cancer, Princess Maria of Romania, Dr Tedros, Director-General of the WHO, "the renowned film director and comedian Woody Allen", who being public figures and credible, persuade to an active and positive behavior and leverage the causes of EURORDIS.

\section{Facebook uses in numbers}

The results of the content analysis reveal that the first two months of the year are the ones the frequency of posts was highest: February with $38(23,8 \%)$ and January with $37(23,1 \%)$. Among the first semester of the year, June is the month poorest in posts: $17(10,6 \%)$.

Regarding the content of posts, and considering specifically the issue, the "reference of an event promoted by EURORDIS" is, distinctively, the most present ( $95-59,4 \%)$, followed by "reference of online resources to facilitate the access to information or/and to promote rare diseases" (34-21,3\%). The other issues have a residual presence. In terms of the type of content, the most used type is "information and appeal" (64-40,0\%). The appealing type is the second one more frequent, with almost $30 \%$, and the informative type has an incidence of almost $20 \%$.

In terms of form or style, each post uses text, but the most used type of resource is "text and photo" (124-77,5\%), followed by "only text" $(24-15,0 \%)$ and, at last, "text and video" $(12-7,5 \%)$. Among the rhetorical devices used $(\mathrm{N}=103)$, the most frequent is "use of question" with more than $40 \%$ (see table 1 ).

Table 1. Rhetorical devices

\begin{tabular}{|l|c|c|}
\hline & $\mathbf{N}$ & $\%$ \\
\hline Use of question & 43 & 41,7 \\
\hline Personalization & 25 & 24,3 \\
\hline Exclamation point & 22 & 21,4 \\
\hline Statistical data & 4 & 3,9 \\
\hline Factual data & 4 & 3,9 \\
\hline Mix of information and appeal & 3 & 2,9 \\
\hline Pleonasm / redundancy & 1 & 1 \\
\hline Antithesis & 1 & 1 \\
\hline Total & $\mathbf{1 0 3}$ & $\mathbf{1 0 0}$ \\
\hline
\end{tabular}


Interactivity

Interactivity is measured using the arithmetic mean (or average), a measure of central location, and the mean of likes is 23,75 . The mean of shares is 8,56 and the mean of comments is 0,91 . This signifies that, in total, there is an amount of 23,75 likes, 8,56 shares, and 0,91 comments per post. The most liked (76 likes) post is published on March 15 and refers to an event, concretely to the EURORDIS winter school. The most sharable post is published on the same day and is related to an appeal to "don't miss the chance to make your voice heard", by participating in the \#RareBarometer survey. The most commented post (13 comments) is published on January 18, and focuses on a personal story, the story of Richard West, the recipient of the EURORDS Volunteer Award in recognition of his "admirable commitment of over 20 years as a dedicated advocate of rare disease issues on behalf of the Behçet's community".

In summary, the most interactive messages are those that promote events, those that motivate publics to have an audible voice and personalized stories that attract the recipient's identification and projection. Facebook allows events to gain visibility and breadth, organizations and their activities to penetrate larger networks of people, and patients and members to improve interactions and to expand the accessibility to messages of their interest. In addition, Facebook is a promotor of inclusion, visibility, identification, inspiration, incitement, and action.

\section{Trying to press the press: The communicational potential of EURORDIS' press releases}

Thematic agenda. The qualitative content analysis reveals four issues: 1. public support/promotion of actions benefiting the cause of rare diseases (e.g., "EURORDIS calls for holistic care for the 30m people living with a rare disease in Europe by 2030", "Rare Disease Day 2019 Policy Event at the United Nations", "Takeda, Microsoft and EURORDIS release report with action plan to help rare disease community shorten the diagnostic odyssey"), 2. results of surveys on rare diseases (e.g., "Close to $100 \%$ of respondents are supportive of data-sharing initiatives to foster research and improve healthcare", "over $40 \%$ are against their data being shared outside the medical field"), 3. results of EURORDIS' efforts (e.g., "The United Nations Office of the High Commissioner for Human Rights (OHCHR) has made reference to persons living with a rare disease within its recently published annual report"); and 4. advocacy successes (e.g., "Rare diseases feature for first time at World Health Assembly").

In 2018, EURORDIS launches eight press releases and, during January and August of 2019, nine press releases. All the EURORDIS' press releases reflect the efforts and activity of the organization.

The most approached issue, in the press releases, is "public support/promotion of actions benefiting the cause of rare diseases" (14). Each one of the other issues ("results of surveys on rare diseases", "results of EURORDIS' efforts", "advocacy successes") has one presence. All issues lay emphasis on the merit of EURORDIS.

Sources. The most frequent sources are EURORDIS direction and institutional voice (12), followed by various organizations related to rare diseases and health (4) and intergovernmental organizations (United Nations - UN) (1).

Rhetorical devices. In terms of rhetorical devices, the personalization, present specially by the use of citations and specific positions, is the most frequent, concretely in the content 
of eight press releases. Factual data, with seven presences, is the second one. At last, it was used statistical data in two press releases.

Results of rhetorical analysis show attention to the target public - journalists -, by using a predominantly informative and objective language style. The ethos is present through the use of official and institutional sources and, therefore, credible as: EURORDIS' direction. The logos is built on facts, statistics and personalization, through the expression of the voices from credible sources.

Content: Patterns versus variations. Use of a predominantly informative and factual language style. 15 of 17 press releases include a presentation of EURORDIS. Only one uses photos.

\section{Discussion and conclusions}

\section{EURORDIS' use of digital media (website and Facebook page) to communicate with patients and members}

This study tries to give some contributions, responding to the OECD/EU's (2018, p. 13) and Davies' diagnosis (2016) of a scarce exploitation by the health systems of new digital technologies to strengthen prevention and care. Recognizing that "health is wealth" (Unger, 2004) and the imperatives and virtues of the "Web PR age" (Hurme, 2001), this article assumes the premise "healthy thanks to communication" (Belim \& Vaz de Almeida, 2018).

The EURORDIS' website tries to be eclectic, providing different types of content - information, clarification, personalization, support, appeal, and empowerment - that can satisfy various needs. The personal stories and the various testimonial videos, for example, play a human role (pathos), inviting the recipient into a more intimate and closer approach to the patient. In addition, the construction of personal stories of suffering helps individuals to understand certain situations (Sharf \& Vanderford, 2003, p. 29). Ramanadhan et al. (2013, p. 7) also mentions that stories with human interest received the highest average number of "likes" per post. It is also noted a media-oriented option, as the website presents an item intitled "EURORDIS press releases", contrasting with the results by the Castillo-Esparcia and López-Villafranca's study (2016), that identify only $21 \%$ of organizations with a virtual press room.

EURORDIS tries to be active in Facebook. The topics, covered in the posts, are diverse, exploring various types of content, such as: informative, appealing, utilitarian (the poster for 2019's rare disease day) and even ludic ("Have your say in choosing the winner of the EURORDIS Photo Award 2019", invitation for \#IntimateAudrey exhibition). The most significative type is "information and appeal" $(40,0 \%)$, followed by appealing type. Discussing these specific results, EURORDIS can be exploiting Facebook as "a great way to build and engage communities of advocates" (Wilson, 2012, p. 67), which can be particularly pertinent in the divulgation of rare diseases, which do not have enough visibility.

The most published issue is "reference of an event promoted by EURORDIS" $(59,4 \%)$, being in coherence with the results by Ramanadhan et al. (2013), that conclude that the most significant issue, published by U.S. 166 CBOs, is organization promotion $(66 \%)$.

There is a predominance of the visual dimension in Facebook, with $77.5 \%$ of posts using text and photo together. This particular result reinforces previous studies on the use of Facebook by rare disease associations (Reguera, 2017; Reguera, Subirats \& Armayones, 2017; Subirats et al. (2018) and meets the trends of "compelling content" (Ehrlich \& Harrigan, 
2019) and of the growing protagonism of the image (Puentes-Rivera, Rúas-Araújo \& Dapena-González, 2017, p. 86).

The rhetorical devices used in Facebook's messages, to communicate with patients and members, make them more attractive and motivate for persuasion, the essence of rhetorical theory: a) the question as a phatic or flashy element, which establishes contact, since demands a response; b) repetition: some initiatives and events are remembered in order to optimize the reception of the message and familiarity with it. The repetition favors the memory performance, that can be enhanced and maintained for a long time (Zhan, Guo, Chen \& Yang, 2018); c) the information appears as a partner of the appeal, constructing and improving the potential of a discourse that is mainly entangled in the informational and appeal functions; d) exemplification and personalization by referring to people who experience illnesses, encouraging empathy and identification of people who deal and not deal with same diseases and disorders, and to those involved in the promotion of causes related to rare diseases, stimulating a supportive and empathic spirit (pathos); e) exclamation point is used as a phatic element and, thus, acts as a magnet for the reader's attention; f) the reference to "elite figures" makes the speech credible. Hovland group confirmed that communicators high in expertise and trustworthiness (such as medical specialists) tend to be more persuasive (Ajzen, 1992, p. 5); and g) the factual and statistical data and style resources help to persuade. For Aristotle (IV century/2005), proof and demonstration are fundamental in discourse (p. 49). Style figures concretize and clarify the sender's speech (Corbett, 2004, 143). The use of examples gives a better illustration of the speaker's statement (Petric, 2007, p. 263).

\section{Constructing messages on rare diseases to journalists}

All the EURORDIS' press releases reflect the efforts and activity of the organization, since the aim is to promote it and how public relations practitioners frame their health messages to the media may have a direct impact on the public's health perceptions and decisions (Ruăo et al., 2012, pp. 69-70; Tanner, 2004b, p. 24). The most significant issue, in the press releases, is "public support/promotion of actions benefiting the cause of rare diseases" (14), being in line with the result by Park and Reber's study (2010). The authors stand out that, to demonstrate their initiatives for public health, the three organizations analyzed employed most frequently the social support/educational frame.

The use of EURORDIS' direction and institutional voice as the main quoted sources reinforces the position and an intervention's image of the organization. All the sources used are institutional, fulfilling the criterion of ethos - the reference to elite members. In the journalistic praxis, this type of sources facilitates the task of confirming sources and injects credibility into the news discourse. Lee (2016), analyzing the use of quotations in offline (The New York Times and The Wall Street Journal) and online (The Huffington Post and Newsmax) newspapers in terms of verb objectivity and source qualification (transparency and credibility), observes that source credibility was the key determinant, followed by verb objectivity, for online papers when analyzed with verb objectivity because source credibility first determines the order of quotation use as a whole followed by verb objectivity (p. 13).

The logos is built on facts, statistics and personalization, through the expression of the voices from credible sources. This rhetorical tactic is in accordance with journalistic language style. Turk (1986) adverts that the conformity to journalistic norms of newsworthiness is the most important factor in a newspaper's decision to accept a news release and this style solves 
the problem identified by Friedman et al. (2013) that journalists faced personal difficulties in understanding public health information due to "many people with public health degrees become epidemiology-focused and not media-focused" (p. 383).

However, only one press release used photos. Ehrlich and Harrigan (2019) explain that, with a strong headline in place, adding captivating visuals will increase the appeal of the news release. The authors suggest to "show your story, don't tell it", once research finds out that approximately $65 \%$ of today's audiences are "visual-first" and that multimedia increases open rates by $200 \%$ over traditional text-only news releases.

\section{Takeaways}

Given the conclusion by Bañón Hernández (2007) that patients with rare diseases, because of their systematic exclusion from the main discussion forums, are considered a minority group with generally little capacity to exert any significant influence on political and social issues, all means and resources will be welcome to give voice to patients with rare diseases. Subirats et al. (2018), previously, made some recommendations regarding the Facebook (e.g. use photos in their posts; update their status; post content of common interest and post at midday or late at night), that can be adopted in the e-PR's performance.

Grounded on the results of the present investigation, it can be recommended regarding the online performance of e-PR in website and Facebook page: 1. Diversification of contents in order to satisfy different needs of publics; 2 . Reference of personal stories that promote proximity, inclusion, inspiration, incitation, empathy; 3 . Promotion of events and, inherently, promotion of the health organization, accomplishing the aim of showing the amplitude of activities and dynamism of the health organization; 4. Use of various resources and channels - integrated communication - to motivate the engagement and empowerment of communities and to give visibility to rare diseases; 5 . Exploration of the visual dimension; 6. Use of rhetorical devices, such as the question point, the repetition, the articulation between information and appeal, the exemplification and the personalization, the exclamation point, the reference to credible and "elite figures", factual and statistical data, style devices.

Regarding the communication through press releases with journalistic public, it can be recommended to health organizations : 1 . the public support / promotion of actions benefiting the cause of rare diseases as frame; 2 . institutional and credible sources as sources of information; 3. narration based on facts, statistics, and personalization; 4. a rhetorical strategy in accordance with journalistic language style, i.e., a more media-oriented approach; 5. use of captivating visuals to increase the appeal.

These are the tactics that compose the rhetorical strategy that a health organization, regarding e-PR, can use "to make the most convincing argument that will persuade publics to agree with them" (Inoue, 2018) and, answering to Campbell's challenge (2017, pp. 8, 12), the rhetorical contributions to health pedagogy and to the understanding of health communication practices. All the options of EURORDIS's e-PR described reflect the approach of rhetorical theory, that advocates the effort to shape knowledge, images and opinions, as well to be convincing and motivating others.

The theory also features how the PR process becomes enriched through the role co-created. Online health communities, as the ones EURORDIS constitutes through online channels, can function as platforms for co-creation. In this sense, social media technologies "enable individuals around the globe to connect with each other to share and exchange information 
via virtual platforms" (Amann \& Rubinelli, 2017). For example, the level of interactivity in the corpus analyzed reveals that, in total, there is an amount of 23,75 likes, 8,56 shares, and 0,91 comments per post. Shared meaning functions socially as a blend of mind and self (Heath $\&$ Frandsen, 2008). Through this via, PR can add value to society by assuring that health choices become enlightened, risks are ethically managed, and relationships are mutually developed (Black, 2014, p. 36).

\section{Future investigation}

Other researches can be done, increasing the number of cases of health organizations being studied, and more studies on the health effects of e-PR on the public should also be conducted.

e-PR has tremendous challenges, as it deals with "the minds and hearts of people" and, concretely in health field, manages two major resources: "communication is what makes us human" (Macnamara, 2017) and "health is wealth" (Unger, 2004).

\section{References}

Ajzen, I., (1992). Persuasive communication theory in social psychology: A historical perspective. Amherst: University of Massachusetts.

Altheide, D. L. (2004). Ethnographic content analysis. In M. S. Lewis-Beck, A. Bryman \& T. F. Liao. (Eds.). The Sage encyclopedia of social science research methods, 3 vols (pp. 325-326). Thousand Oaks, CA: Sage.

Amann, J., \& Rubinelli, S. (2017). Views of community managers on knowledge co-creation in online communities for people with disabilities: Qualitative study. Journal of Medical Internet Research. 19(190), e320.

Aristotle (IV century BC/2005). Retórica. Lisboa: Imprensa Nacional-Casa da Moeda.

Bañón Hernández, A. M. (2007). Las enfermedades raras y su representación discursiva. Propuestas para un análisis crítico. Discurso \& Sociedad. 2(1), 188-229.

Bañón Hernández, A. M., Alcaraz, J. F., Almela, J. S., \& Sanchis, I. R. (2011). Desafios y estrategias comunicativas de las enfermedades raras: La investigación médica como referente: Estudio cuantitativo-discursivo de la prensa escrita impresa y digital española (2009-2010). Valencia: CIBERER.

Belim, C., \& Vaz de Almeida, C. (2017). Healthy thanks to communication: A model of communication competences to optimize health literacy: Assertiveness, clear language, and positivity. In V. E. Papalois \& M. Theodospoulous. (Eds.). Optimizing health literacy for improved clinical practices (pp. 124-152). Hershey, PA: IGI Global.

Bernays, E. L. (2013). Public relations. Norman, OK: University of Oklahoma Press.

Black, A. P., \& Baker, M. (2011). The impact of parent advocacy groups, the Internet, and social networking on rare diseases: the IDEA League and IDEA League United Kingdom example. Epilepsia. 52(Suppl 2), 102-104.

Black, C. (2014). The PR professional's handbook: Powerful, practical communications. London: Kogan Page.

Bouwman, M. G., Teunissen, Q. G. A., Wijburg, F. A., \& Linthorst, G. E. (2010). 'Doctor Google' ending the diagnostic odyssey in lysosomal storage disorders: Parents using internet search engines as an efficient diagnostic strategy in rare diseases. Archives of disease in childhood. 95(8), 642-644.

Bowen, S. A., Hung-Baesecke, C.-J. F., \& Chen, Y.-R. R. (2016). Ethics as a precursor to organization-public relationships: Building trust before and during the OPR model. Cogent Social Sciences. 2(1). doi:10. 1080/23311886.2016.1141467

Bryman, A. (2012). Social records methods. New York: Oxford University Press.

Burke-Garcia, A., \& Scally, G. (2014). Trending now: Future directions in digital media for the public health sector. J. Public Health. 36(4), 527-534.

Burke, K. (1969). A rhetoric of motives. Berkley, CA: University of California Press. 
Campbell, L. (2017). The rhetoric of health and medicine as a "teaching subject": Lessons from the medical humanities and simulation pedagogy. Technical Communication Quarterly. 27(1), 7-20. doi:10.1080/ 10572252.2018.1401348

Carpenter, D. M., Blalock, S. J., \& DeVellis, R. F. (2012). Patients with rare diseases using pharmacists for medication information. J Am Pharm Assoc. 52(6), e175-182.

Castillo-Esparcia, A., \& López-Villafranca, P. (2016). Communication strategies employed by rare disease patient organizations in Spain. Ciência \& Saúde Coletiva. 21(8). Retrieved September 12, 2019, from http://www.scielo.br/scielo.php?pid=S1413-81232016000802423\&script=sci_arttext\&tlng=en.

Cho, S. (2006). Network news coverage of breast cancer, 1974 to 2003. Journalism and Mass Communication Quarterly. 83(1), 116-130.

Corbett, E. (2004). Classical Rhetoric. In J. Rivkin \& M. Ryan. (Eds.). Literary theory, an anthology (pp. 142-161). Maiden: Blackwell Publishing.

Cuenca Fontbona, J. (2012). Las auditorias de relaciones públicas. Barcelona: Editorial UOC.

Davies, W. (2016). Insights into rare diseases from social media surveys. Orphanet J. Rare Dis. 11, 151.

Davis, A. (2000). Public relations, news production and changing patterns of source access in the British national media. Media. Culture \& Society. 22(1), 39-59.

Doyle, M. (2015). Peer Support and Mentorship in a US Rare Disease Community: Findings from the Cystinosis in Emerging Adulthood Study. Patient. 8(1), 65-73.

Dwyer A. A., Quinton R., Morin D., \& Pitteloud N. (2014). Identifying the unmet health needs of patients with congenital hypogonadotropic hypogonadism using a web-based needs assessment: implications for online interventions and peer-to-peer support. Orphanet J Rare Dis. 9(1), 1-11.

Dysart-Gale, D. (2010). Techne, technology, and disenchantment in the wind in The Wind in the Willows. In J. C. Horne \& D. R. White. (Eds.). Kenneth Grahame's the wind in the willows: A children's classic at 100. Lanham: Scarecrow Press.

Edwards, L. (2018). Understanding public relations: Theory, culture and society. London: SAGE.

Ehrlich, S., \& Harrigan, D. (2019). Three trends to adopt for better news release results". Public Relations Today. Retrieved September 12, 2019, from https://www.publicrelationstoday.com/2019/trends/?open-article-id=11208301\&article-title=three-pr-trends-to-adopt-for-better-news-release-results\&blogdomain=businesswire.com\&blog-title=business-wire.

Friedman, D. B., Tanner, A., \& Rose, I. D. (2014). Health journalists' perceptions of their communities and implications for the delivery of health information in the news. Journal of Community Health. 39, 378-385.

Gass, R. H., \& Seiter, J. S. (2010). Persuasion, social influence, and compliance gaining. Boston: Allyn \& Bacon.

Grunig, J. E., \& Hunt, T. (1984). Managing public relations. New York: Holt, Rinehart and Winston.

Haig, M. (2000). The essential guide to public relations on the Internet. London: Kogan Page.

Heath, R. L., \& Frandsen, F. (2008). Rhetorical perspective and public relations: Meaning matte. In A. Zerfass, B. van Ruler, \& K. Sriramesh. (Eds.). Public relations research: European and international perspectives and innovations (pp. 349-364). Wesbaden, Germany: VS Verlag.

Hilton-Kamm, D., Sklansky, M., \& Chang, R. K. (2014). How not to tell parents about their child's new diagnosis of congenital heart disease: An Internet survey of 841 parents. Pediatr. Cardiol. 35(2), 239-252.

Howell, K. (2012). An introduction to social networks. In S. Waddington. The social media handbook for PR professionals (pp. 3-12). Sussex, UK: John Wiley \& Sons.

Hurme, P. (2001). Online PR: emerging organisational practice. Corporate Communications: An International Journal. 6(2), 71-75.

Ihlen, Ø. (2008). Rhetorical theory of public relations. In W. Donsbach. (Ed.). The Blackwell International Encyclopedia of Communication (pp. 4395-4397). Oxford, England: Blackwell.

Inoue, T. (2018). Public relations in hyper-globalization: Essential relationship management - A Japan perspective. NY: Routledge.

Jhaveri, K. D., Schrier, P. B., \& Mattana, J. (2013). Paging Doctor Google!. Heuristics vs. technology. F1000Research. 2(90), 1-15.

Ki, E.-J., Kim, J.-N., \& Ledingham, J. A. (Eds.). (2015). Public relations as relationship management: A relational approach to the study and practice of public relations. NY: Routledge. 
Kite, J., Foley, B. C., Grunseit, A. C., \& Freeman, B. (2016). Please like me: Facebook and public health communication. PLOS ONE. 11(9), e0162765.

Kowalski, C., Kahana, E., Kuhr, K., Ansmann, L., \& Pfaff, H. (2014). Changes over time in the utilization of disease-related internet information in newly diagnosed breast cancer patients 2007 to 2013. J Med Internet Res. 16(8).

L'Etang, J. (2006). Public relations in sport, health and tourism. In J. L'Etang \& M. Pieczka. (Eds.). Public relations: Critical debates and contemporary practice (pp. 241-262). Mahwah, New Jersey: Lawrence Erlbaum Associates.

Lalazaryan, A., \& Zare-Farashbandi, F. (2014). A Review of models and theories of health information seeking behavior. International Journal of Health System \& Disaster Management. 2(4), 193-203.

Lasker, J. N., Sogolow, E. D., \& Sharim R. R. (2005). The role of an online community for people with a rare disease: content analysis of messages posted on a primary biliary cirrhosis mailinglist. $J$ Med Internet Res. 7(1), e10.

Lee, G. (2016). Verb objectivity and source qualification: Comparison of quotation attributions in offline and online newspapers. Journalism: Theory, Practice \& Criticism. 18(7), 890-906.

Levine, M. (2003). A branded world: Adventures in public relations and the creation of superbrands. Hoboken, New Jersey: John Wiley \& Sons, Inc.

Lipschultz, J. H. (2015). Social media communication: Concepts, practices, data, law and ethics. NY: Routledge.

Liuccio, M., Belotti, R., Comune, A., Zambito, V., \& Schulz, P. J. (2015). Communication in rare diseases: A literature review. Journal of Communication Research. 7(3), 2-10.

Lopes, F., Ruăo, T., Marinho, S., \& Araújo, R. (2011). Jornalismo de saúde e fontes de informaçăo, uma análise dos jornais portugueses entre 2008 e 2010. Derecho a Comunicar. (2), 100-120.

Lynch, J. A., \& Zoller, H. (2015). Recognizing differences and commonalities: The rhetoric of health and medicine and critical-interpretive health communication. Communication Quarterly. 63(5), 498-503. doi:10.1080/01463373.2015.1103592

Macnamara, J. (2017). Evaluating public communication: Exploring new models, standards, and best practice. Abington, UK: Routledge.

Marlow, E. (1996). Electronic public relations. Belmont, CA: Wadsworth.

McKie, D., \& Munshi, D. (2011). Reconfigurar las Relaciones Públicas. Ecología, equidad y empresa. Barcelona: UOC.

Moorhead, S. A. (2017). Social media for healthcare communication. Oxford Research Encyclopedias. Retrieved September 12, 2019, from https://oxfordre.com/communication/view/10.1093/acrefore/9780190228613.001.0001/acrefore-9780190228613-e-335.

Murray, A. (2010). Effective PR: Be your own expert: Teach yourself. London: Hachette.

Mursch K., \& Behnke-Mursch J. (2003). Internet-based interaction among brain tumour patients. Analysis of a medical mailing list. Zentralbl Neurochir. 64(2), 71-75.

Newsom, D., \& Haynes, J. (2010). Public relations writing: Form and style. Wadsworth: Publishing Company.

O'Donohue, W. (2013). Clinical psychology and the philosophy of science. Switzerland: Springer.

OECD/EU (2018). Health at a Glance: Europe 2018: State of health in the EU cycle. Paris: OECD Publishing. Retrieved September 12, 2019, from https://doi.org/10.1787/health_glance_eur-2018-en.

Pang, A., Shin, W., Lew, Z., \& Walther, J. B. (2016). Building relationships through dialogic communication: organizations, stakeholders, and computer-mediated communication. Journal of Marketing Communications. 24(1), 68-82. doi:10.1080/13527266.2016.1269019

Park, H., \& Reber, B. H. (2010). Using public relations to promote health: A framing analysis of public relations strategies among health associations. Journal of Health Communication. 15(1), 39-54.

Petric, B. (2007). Rhetorical functions of citations in high- and low-rated master's theses. Journal of English for Academic Purposes. 6(3), 238-253.

Petrovici, M. A. (2014). E-Public Relations: Impact and Efficiency. A Case Study. Procedia - Social and Behavioral Sciences. 141, 79-84.

Phillips, D., \& Young, P. (2009). Online public relations: A practical guide to developing an online strategy in the world of social media. London: Kogan Page Limited. 
Puentes-Rivera, I., Rúas-Araújo, J., \& Dapena-González, B. (2017). Candidatos en Facebook: Del texto a la imagen. Análisis de actividad y atención visual. Revista DÍGITOS. 3, 51-93.

Ramanadhan, S., Mendez, S. R., Rao, M., \& Viswanath, K. (2013). Social media use by community-based organizations conducting health promotion: a content analysis. BMC Public Health. 13(1).

Reguera, N. (2017). Las enfermedades raras en grupos de Facebook: Evaluación de la línea de actuación de FEDER mediante minería de textos. Master's thesis. Universitat Oberta de Catalunya, Barcelona, Spain.

Reguera, N., Subirats, L., \& Armayones, M. (2017). Mining Facebook data of people with rare diseases. Proceedings of 2017 IEEE 30th International Symposium on Computer-Based Medical Systems (CBMS), Thessaloniki, Greece, 22-24 de junio, pp. 588-593.

Ruăo, T., Lopes; F., Marinho, S., \& Araújo, R. (2012). Media relations and health news coverage: The dialogue on Influenza A in Portugal. In G. Gonçalves. (Org.). The dialogue imperative: Trends and challenges in strategic and organisational communication (pp. 63-80). Covilhă: LabCom Books.

Sak, G., Diviani, N., Allam, A., \& Schulz, P. J. (2015). Comparing the quality of pro- and anti-vaccination online information: a content analysis of vaccination-related webpages. BMC Public Health. 16(1).

Sarf, B., \& Vanderford, M. (2003). Illness narratives and the social construction of health. In T. Thompson, A. Dorsey, K. Miller \& R. Parrott. (Eds.). Handbook of health communication (pp. 9-34). New Jersey: Lawrence Erlbaum Associates.

Subirats, L., Reguera, N., Bañón, A., Gómez-Zúñiga, B., Minguillón, J., \& Armayones, M. (2018). Mining Facebook data of people with rare diseases: A content-based and temporal analysis. International Journal of Environmental Research and Public Health. 15(9), 1877.

Tanner, A. H. (2004a). Agenda Building, Source Selection, and Health News at Local Television Stations. A Nationwide Survey of Local Television Health Reporters. Science Communication. 25(4), 350-363.

Tanner, A. H. (2004b). Communicating health information and making the news: Health reporters reveal the PR tactics that work. Public Relations Quarterly. 49(1), 24-27.

Turk, J. V. (1986). Information subsidies and media content: A study of public relations influence on the news. Journalism Monographs. (100). Columbia, SC: AEJMC.

Unger, F. (2004). Health is wealth: Strategic visions for European healthcare at the beginning of the 21st century. Report of the European Parliament. Berlin: Springer.

Vasquez, G. M., \& Taylor. M. (2001). Research perspectives on "the public". In R. L. Heath. (Ed.). Handbook of public relations (pp. 139-154). London: Sage.

Watson, T., \& Noble, P. (2014). Evaluating public relations. London and Philadelphia: Kogan Page.

Wicks P., Massagli M., Frost J., Brownstein C., Okun S., Vaughan T., Bradley R., \& Heywood J. (2010). Sharing health data for better outcomes on PatientsLikeMe. J Med Internet Res. 12(2), e19.

Wilson, R. (2012). Facebook: A way to engage with your audiences. In S. Waddington. The social media handbook for PR professionals (pp. 61-70). Sussex, UK: John Wiley \& Sons.

Zaid, T., Burzawa, J., Basen-Engquist, K., Bodurka, D. C., Ramondetta, L. M., Brown, J., \& Frumovitz, M. (2014). Use of social media to conduct a cross-sectional epidemiologic and quality of life survey of patients with neuroendocrine carcinoma of the cervix: A feasibility study. Gynecol Oncol. 132(1), 149-153.

Zhan, L., Guo, D., Chen, G., \& Yang, J. (2018). Effects of repetition learning on associative recognition over time: Role of the hippocampus and prefrontal cortex. Frontiers in Human Neuroscience. 12. doi:10.3389/fnhum.2018.00277

Zoch, L. M., \& Molleda, J. C. (2006). Building a theoretical model of media relations using framing, information subsidies and agenda building. In C. H. Botan \& V. Hazleton. (Eds.). Public relations theory II (pp. 279-309). Mahwah, NJ: Lawrence Erlbaum. 